\title{
Mass Spectrometric and Rapid Electrochemical Detection and Reductive Dehalogenation of Triclosan
}

Janine Rizos and Achim Habekost ${ }^{\star}$

Department of Chemistry, University of Ludwigsburg, Ludwigsburg, Germany

*Corresponding author: Achim Habekost, Department of Chemistry, University of Ludwigsburg, Ludwigsburg, Germany, Tel: 0049-7141-140-332; E-mail: A.Habekost@t-online.de

Received date: March 26, 2018; Accepted date: April 03, 2018; Published date: April 09, 2018

Copyright: (c) 2018 Rizos J, et al. This is an open-access article distributed under the terms of the Creative Commons Attribution License, which permits unrestricted use, distribution, and reproduction in any medium, provided the original author and source are credited.

\begin{abstract}
Triclosan is a chlororganic substance used as a bactericide in numerous cosmetics. Intensive triclosan use results in the exposure into the environment; therefore, it is vital to analyze and detoxify triclosan-contaminated wastewater, sludge and soil.

This study investigates two analytical strategies. The first is a rapid and inexpensive electrochemical screening technique based on commercial Screen-Printed Electrodes (SPE), which delivers initial results suitable for field measurements and screening. The second is Gas Chromatography-Mass Spectrometry (GC-MS), which is more sophisticated, accurate and sensitive. This latter method can provide more reliable determination of triclosan, e.g., for suspicious samples. We tested the limits of triclosan detection for different electrochemical methods and compared these to mass spectrometry with and without derivatization of triclosan.

In addition to these analytical techniques, gas phase dehalogenation was used to dechlorinate triclosan. Reductive dechlorination of triclosan occurs efficiently at moderately elevated temperatures $\left(350-550^{\circ} \mathrm{C}\right)$ with zero valent iron. In contrast to oxidative processes, reductive dehalogenation leads to harmless and completely dechlorinated products.
\end{abstract}

Keywords: Triclosan; Electrochemical and mass spectrometric detection; Reductive dechlorination

\begin{abstract}
Abbreviations:
GC-MS: Gas Chromatography-Mass Spectrometry; MS: Mass Spectrometry; SPE: Screen-Printed Electrodes; DPV: Differential Pulse Voltammetry; ECL: Electrogenerated Chemiluminescence; HPLC: High-Performance Liquid Chromatography; LOD: Limit of Detection.
\end{abstract}

\section{Introduction}

Triclosan (5-Chlor-2-(2,4-dichlorophenoxy)-phenol), (Figure 1) is a bactericide used in numerous everyday products (e.g., in cosmetics such as toothpaste, deodorants and soaps, and in various antiseptics). Triclosan can act as an endocrine disruptor and can cause allergic reaction. The maximum accepted concentration in cosmetics is $0.3 \%$ [1]. In low concentrations triclosan is bacteriostatic, while at higher concentrations triclosan is bactericidal [2-5]. The acceptable level for the presence of triclosan in drinking water reflects the No Observed Adverse Effect Level (NOAEL) and can reach several mg/L [6].

The use of triclosan is controversial because it is not clear whether it influences antibiotic and cross-resistance. The authors of a metaanalysis ordered by the European Commission concluded that it is currently not possible to properly estimate the risks of triclosan [1]. But the high levels of triclosan used mean that considerable amounts are released into the environment.

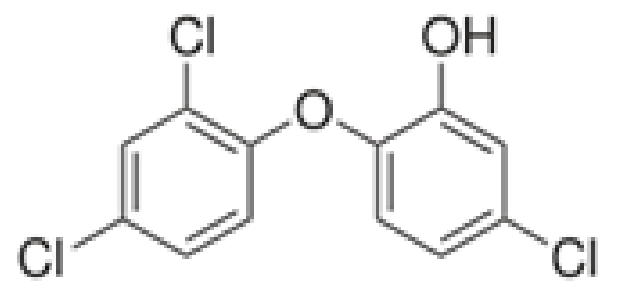

Figure 1: Structure of Triclosan.

The SciFinder database contains more than 11,000 articles with the keyword "triclosan". In the last few years, investigations have primarily focused on analytics, the fate of triclosan in wastewater, sludge and sediments and the extraction and (oxidative) degradation of triclosan [7-12]. In addition to MS and HPLC analysis [13], and to a lesser extent spectrophotometric analysis [14], electrochemical investigations are common because the electrochemical device is simple and the analysis (e.g., of wastewater or sewage sludge) can be done on-site. New electrode materials such as nanorods [15], carbon quantum dots [16], electrodes modified with $\mathrm{TiO}_{2}$ [17] are used, as well as SPE [18]. A review of the electrochemical methods is provided by Montaseri and Forbes [19].

Solid-phase extraction is widely used for sample extraction and analyte enrichment. Materials such as octadecyl bonded silica cartridge $[20,21]$ and other extracting agents such as different 
Citation: Rizos J, Habekost A (2018) Mass Spectrometric and Rapid Electrochemical Detection and Reductive Dehalogenation of Triclosan. J

Page 2 of 8

copolymers are used, which exhibit both hydrophilic and hydrophobic characteristics $[22,23]$. Common elution reagents for these cartridge materials include methanol, ethyl acetate, and acetone [24].

Current methods of degradation of triclosan (e.g., in wastewater and sewage sludge) include biological degradations [25], oxidative degradation with Fenton reagent [26,27], photoelectrocatalytical methods with $\mathrm{TiO}_{2}$ [28,29], degradation in sunlight [30], sonoelectrochemical [31] and photocatalytic methods [32], oxidation with different oxidants [33,34], combinations of electrochemical methods and ozone [35,36] and solely electrochemical methods [37]. The kinetics and the mechanism of the (oxidative) degradation are investigated by Gao [38] and Suarez [39].

In this paper, our goal is to detect triclosan with very simple and commercial electrochemical equipment, for a first estimation of the triclosan concentration, and to compare the data with normal GC-MS We also present a dehalogenation method which has already been successfully applied to the dehalogenation of PCBs and brominated diphenylethers $[40,41]$.

\section{Experimental Part}

Chemicals and materials: Triclosan (Sigma 72779), iron powder (1-10 $\mu \mathrm{m}$, Merck 1.03819), derivatizing agent: trimethylchlororsilane (Roth, Germany, 2338.1), dichloromethane (Roth, Germany, 8424.1), tris (2, 2'-bipyridyl)ruthenium (II) chloride (Sigma, 34967), DLproline (Sigma Aldrich, 171824.), buffer (pH 10) (Roth, Germany.

GC-MS: GC: Hewlett-Packard 6890 with HP 5 column, temperature profile: start temperature: $50^{\circ} \mathrm{C}, 2 \mathrm{~min}$ isotherm temperature ramp: $15^{\circ} \mathrm{C} / \mathrm{min}$; end temperature: $270^{\circ} \mathrm{C}, 2 \mathrm{~min}$ isotherm, MSD: HewlettPackard 5973, injection: $1 \mu \mathrm{L}$ ).

UVVIS: photometer (Perkin Elmer, Lambda XLS+).

Electrochemistry: Pt-grids for electrolysis (Hedinger, Germany), potentiostat ( $\mu$ stat 400, DropSens), SPE (DRP-220 Au-AT, Au as working electrode, $\mathrm{Au}$ as counter electrode, $\mathrm{Ag}$ as pseudoreference electrode, DropSens)

Amperometry: HPLC pump (Knauer HPLC pump 64), Rheodyn injection valve, $10 \mu \mathrm{L}$ loop, electrochemical HPLC cell (DRP HPLCELL, DropSens).

Spectroelectrochemistry: Transmission / reflection cell (DRP REFLECELL, DropSens) with fiber optics (DR PROBE, DropSens), light source: HPLC detector 432 with a $\mathrm{D}_{2}$ lamp, Kontron), photomultiplier (Hamamatsu, R4220P with power supply: MH5781).

Electrogenerated chemiluminescence: ECLSTAT (potentiostat + ECL-cell (DropSens)).

Gas phase dehalogenation: Carbolite tubular furnace (HST 12-40, Carbolite Gero), Perfusor VI (B. Brand), $10 \mathrm{~mL}$ syringe.

\section{Mass spectrometric characterization of triclosan}

For gas chromatographic-mass spectrometric analyzation we used different triclosan concentrations in ethanol. Figure 2 shows a detail of the GC for triclosan concentrations between $1 \mathrm{mmol} / \mathrm{L}$ and $0.5 \mu \mathrm{mol} / \mathrm{L}$ (injection volume: $1 \mu \mathrm{L}$ ). Triclosan was identi ied via the NIST MSdatabase (quality $>95 \%$ ), with the mass spectrometer operating in fullscan mode.
As indicated in Figure 3, the Limit of Detection (LOD) is about 0.15 $\mathrm{mg} / \mathrm{L}(=0.52 \mu \mathrm{mol} / \mathrm{L}=0.15 \mathrm{ng}$ in $1 \mu \mathrm{L}$ used $)$. The main fragments are listed in Figure 2c.

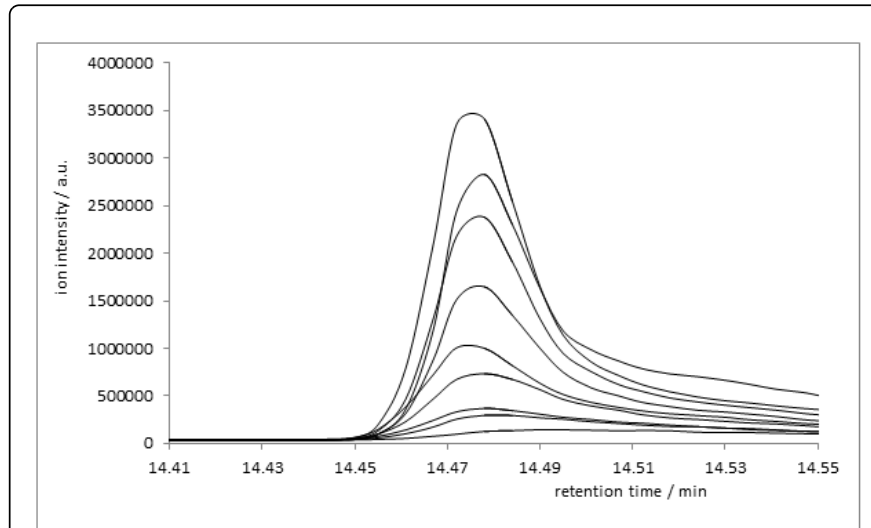

Figure 2a: GC-MS peak triclosan.

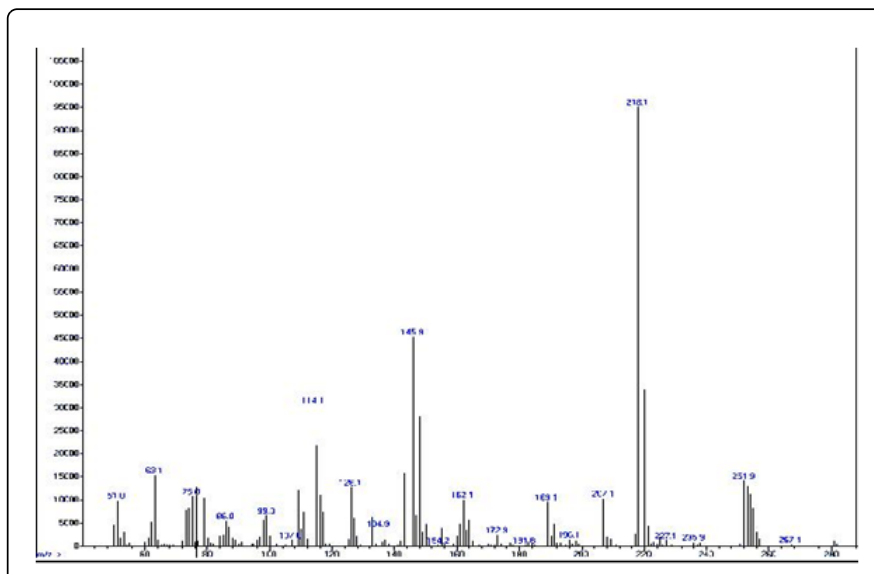

Figure 2b: EI-MS Triclosan.

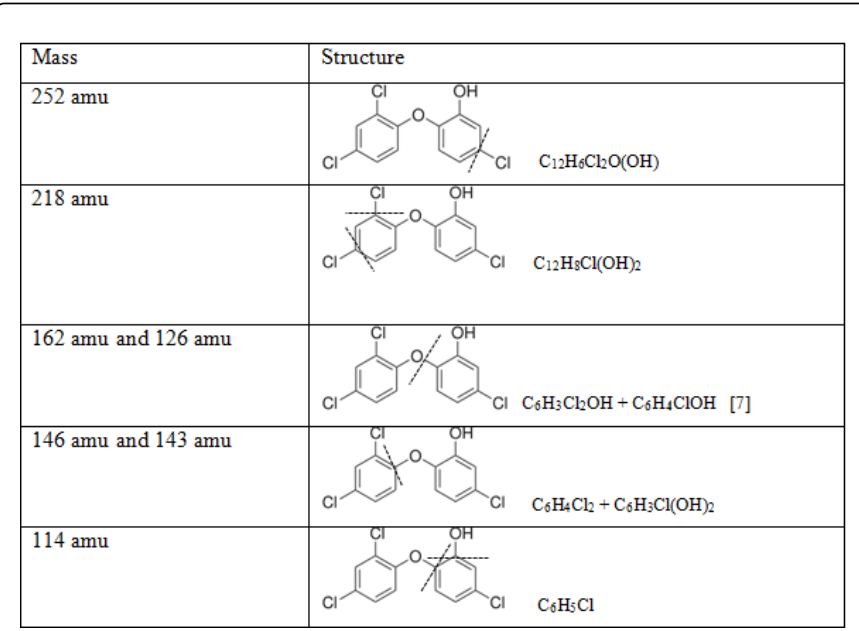

Figure 2c: Selected fragments. 
Page 3 of 8

The ion intensity shows linear concentration dependence from 1.5 ng up to $300 \mathrm{ng}$ triclosan $\left(\mathrm{R}^{2}=0.99\right)$.

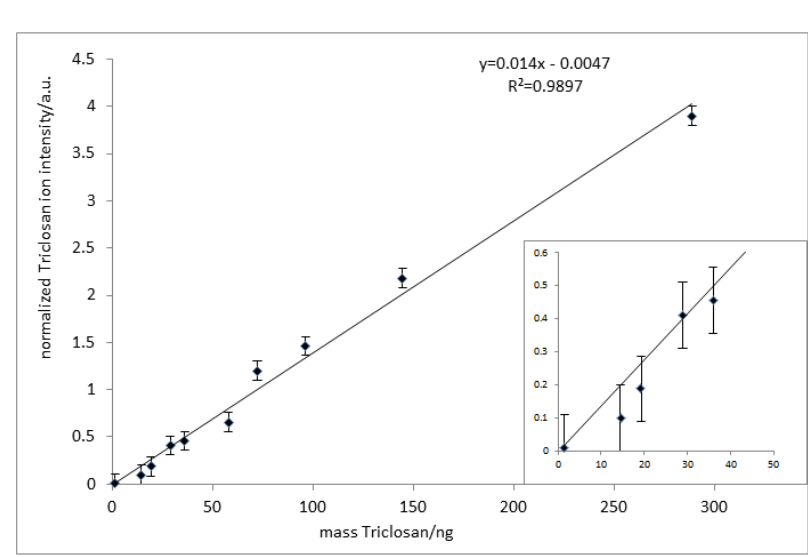

Figure 3: Intensity of the triclosan peak at different triclosan concentrations. Insert: detail.

\section{Derivatization}

Gibson [42] and Yu [23] investigated various acidic pharmaceuticals and a range of potential endocrine disrupting components via GC-MS. They derivatized the substances with different derivatization agents on the basis of methylchlorosilanes. Our goal is to determine whether there is any advantage in derivatizing triclosan. For our study, only one silanization agent was used, since triclosan contains only the phenolic $\mathrm{OH}$ group which forms a trimethylsilyl derivative. Therefore, we compared two triclosan solutions with and without the derivatization agent.

Solution A) contained $100 \mu \mathrm{mol}$ triclosan+150 $\mu \mathrm{mol}$ trimethylchlorosilane $+5 \mathrm{~mL}$ dichloromethane.

Solution B) was the same as solution A), but without trimethylchlorosilane.

Both solutions were heated up to about $50^{\circ} \mathrm{C}$ in a reflux condenser for five hours with subsequent evaporation of the solvent and the excess derivatization agent in a rotary evaporator. At least, we added 1 $\mathrm{mL}$ dichloromethane, respectively. Derivatization was nearly completed. Figure 4 shows the resulting gas chromatograms with and without derivatization.

Unexpectedly, the gas chromatograms show that dichlorodibenzodioxin is formed with and without derivatization agent. We think that dichlorodibenzodioxin is formed at temperatures necessary for the derivatization process. Therefore, we cannot support derivatization. In addition, we found that derivatization does not lead to a lower LOD.

\section{Electrochemical characterization via Differential Pulse Voltammetry (DPV), voltabsorptogram and amperometry}

We tried several SPE and selected a gold electrode, because its sensitivity was highest and the surface is easy to clean (Figure 5). Triclosan can be electrochemically oxidized at his $\mathrm{OH}$ group beginning at $0.3 \mathrm{~V}$. This oxidation is electrochemically irreversible, as indicated by the lack of reduction peak in the cyclic voltammogram (Figure 6). In addition, the oxidation product covers the used gold surface and the second cyclic voltammogram scan shows a significantly lower current. It is well known that the phenoxy radicals produced couple to form a passivating polymeric film on the electrode surface. This electrochemically generated film is strongly adherent and continuous over the electrode surface $[42,43]$. Therefore, the electrode must be cleaned after every measurement. This was done either by polishing the surface with fine aluminum oxide powder or through intense rinsing with ethanol. Thus, the deviation between the current of ten cyclic voltammograms is lower than ten percent.

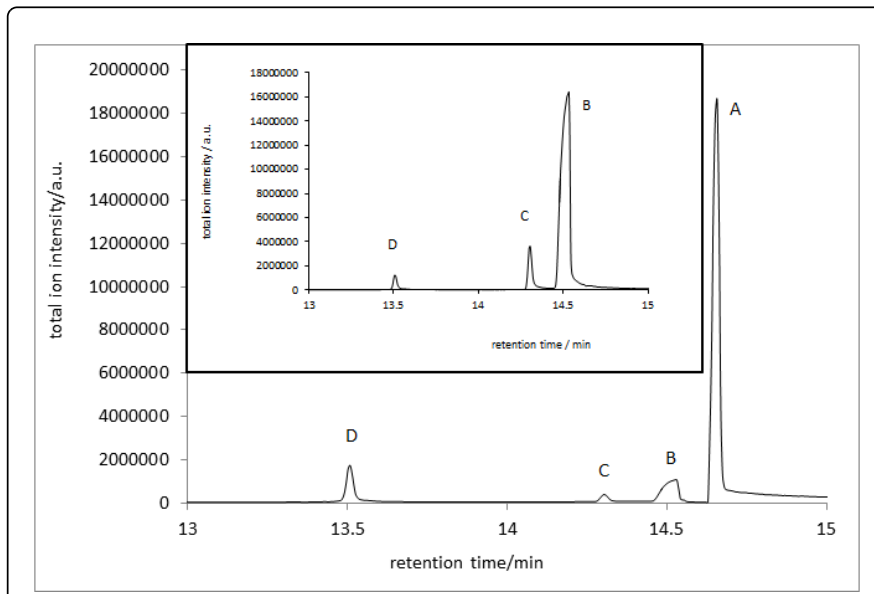

Figure 4: GC-MS of derivated triclosan: A: Triclosan-derivate, B: Triclosan, C: Impurity, D: Dichlorodibenzodioxin. Insert: Without derivatization reagent.

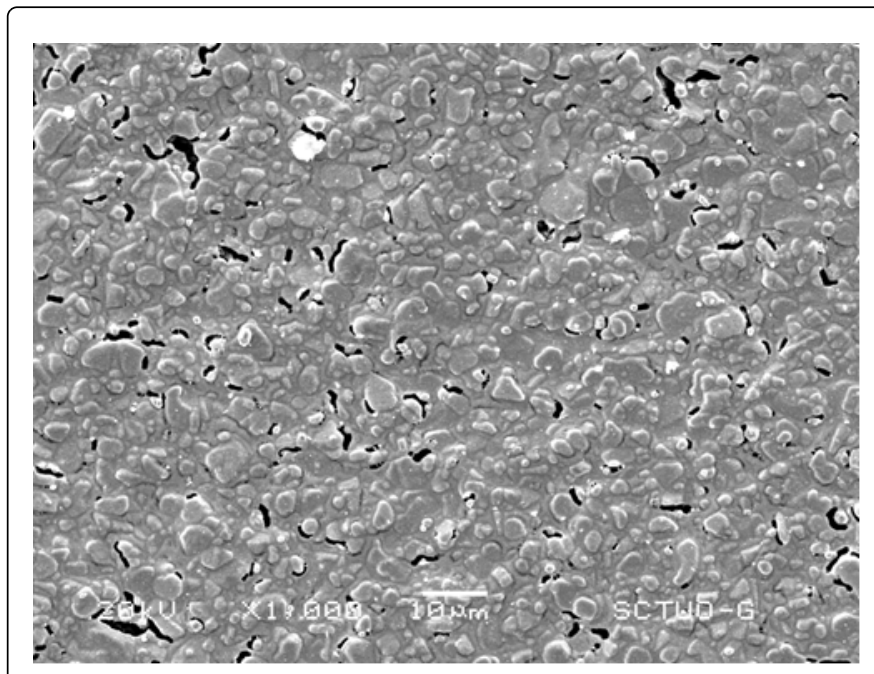

Figure 5: SEM image of the DRP 220AT electrode used. "AT" means the electrode was made with high temperature ink (Image kindly from DropSens).

Dejmkowa [6] showed the $\mathrm{pH}$ dependence of the DP voltammograms of triclosan and found that the currents are maximal at $\mathrm{pH}=10-12$. Therefore, we used buffered solutions of $\mathrm{pH}=10$. 


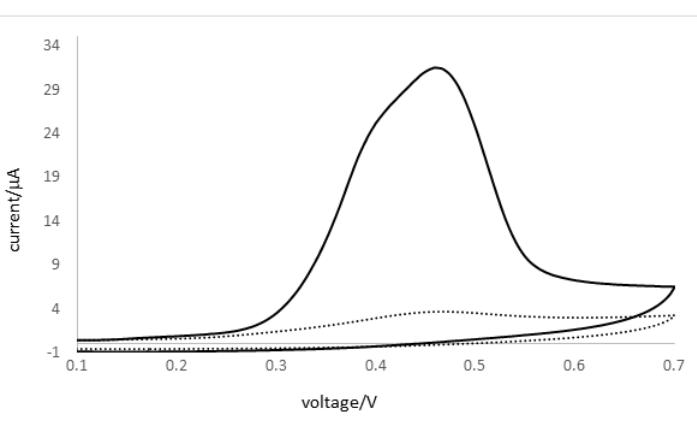

Figure 6: Two successive cyclic voltammograms of triclosan (scan rate: $50 \mathrm{mV} / \mathrm{s}$ ). Solid line: first scan, dotted line: second scan.

For detailed characterization of the oxidation product, we electrolyzed triclosan in a buffer solution $(\mathrm{pH}=10)$ with platinum grid electrodes for $5 \mathrm{~min}(3 \mathrm{~V}, 40 \mathrm{~mA})$ and analyzed the product via UVVIS (Figure 7). The oxidation products show an absorption maximum around $320 \mathrm{~nm}$. Johnson [44] investigated the electrochemical degradation of 4-chlorophenol in an aqueous medium using a platinum anode coated with a quaternary metal oxide film containing $\mathrm{Ti}, \mathrm{Ru}, \mathrm{Sn}$, and $\mathrm{Sb}$ oxides. Liquid chromatography, including reverse phase and ion exchange chromatography, is coupled with electrospray mass spectrometry. The authors identified twenty-six intermediate products. We believe analogous reaction products result in the case of triclosan, but they were not identified.

The electrochemical irreversibility of the oxidation of triclosan can also be demonstrated via spectroelectrochemical measurements: Cyclic voltammogram and absorbance of the triclosan solution at $330 \mathrm{~nm}$ are measured simultaneously. Figure 8 shows the spectroelectrochemical setup employed: Light from a spectrometer is passed with a fiber through the solution ( $60 \mu \mathrm{L}$ volume). The reflected beam (reflection on the gold electrode) is guided through a different fiber into a photomultiplier.

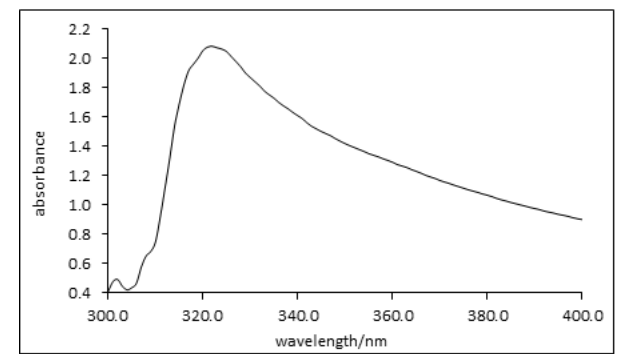

Figure 7: UVVIS spectrum of the oxidation product of triclosan after 5 min electrolysis.

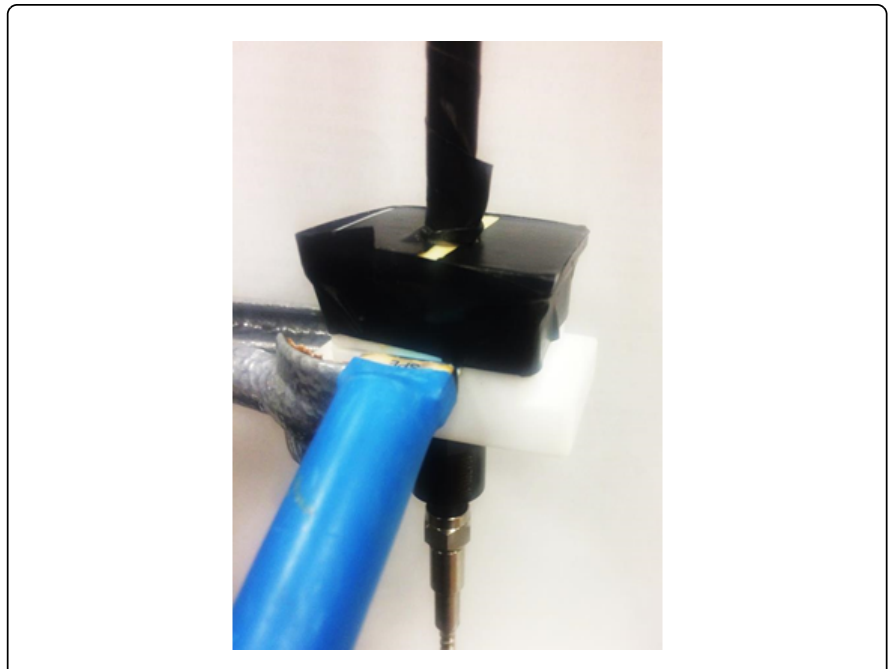

Figure 8: Spectroelectrochemical cell with a fiber from the spectrometer (top). The light $(330 \mathrm{~nm})$ passes the solution and the reflected light (reflection on the Au surface) is collected via a different fiber and is guided into a photomultiplier. The SPE is inside the cell. Bottom: fiber for transmitted light, not used here.

Figure 9 shows both the cyclic voltammogram and the voltabsorptogram at $330 \mathrm{~nm}$. At about $0.3 \mathrm{~V}$ the oxidation of triclosan occurs, and up to about $0.5 \mathrm{~V}$ the absorbance increases until the oxidation is completed. At reverse scan the absorbance remains high, indicating that an irreversible oxidation has taken place in this potential range. The derivative voltabsorptogram at $330 \mathrm{~nm}$ exhibits a complete correlation with the cyclic voltammogram because the two signals are related to the same process.

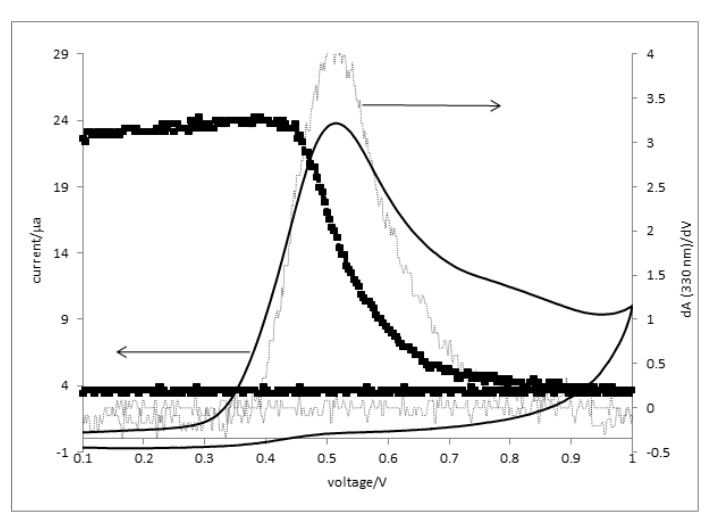

Figure 9: Simultaneous detection of the cyclovoltammogram (solid line) and the voltabsorptogram at $330 \mathrm{~nm}$ (thick points) and derived voltabsorptogram $\mathrm{d}$ (absorbance)/d(voltage) (dotted line) of $1 \mathrm{mmol}$ triclosan in an aqueous solution at $\mathrm{pH}=10$ (scan rate 50 $\mathrm{mV} / \mathrm{s})$.

DPV is a sensitive electrochemical method. Figure 10 shows the results (parameter: EPuls: $50 \mathrm{mV}$, EStep: $5 \mathrm{mV}$, tPuls: $40 \mathrm{~ms}$, scan rate: $30 \mathrm{mV} / \mathrm{s}$ ). The LOD is about 10 times higher than the mass spectrometric method $(=0.7 \mathrm{mg} / \mathrm{L})$. The saturation at higher 
Page 5 of 8

concentrations (not shown in Figure 10) is due to the restriction of the area of the SPE used $\left(=0.125 \mathrm{~cm}^{2}\right)$.

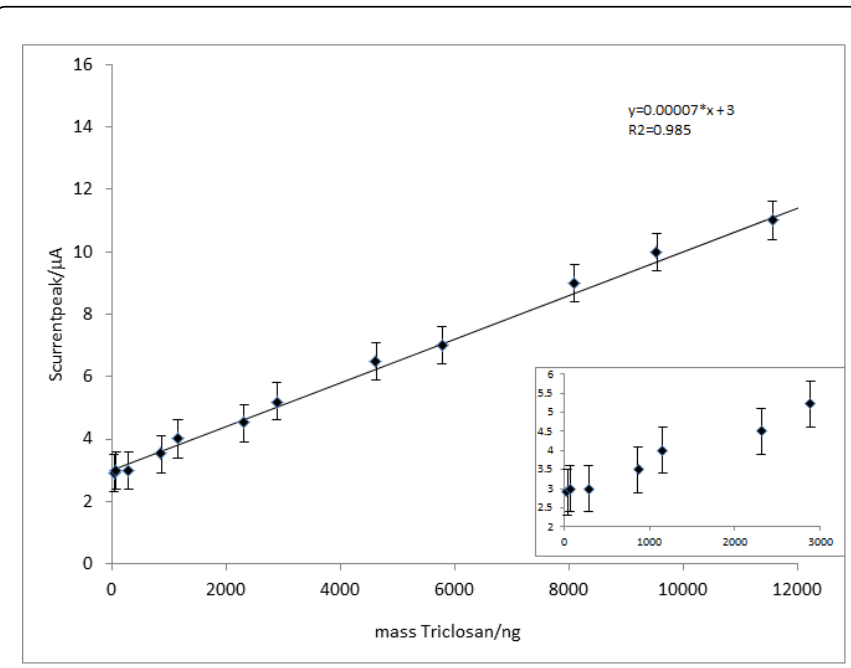

Figure 10: DPV current as a function of triclosan concentration. The arrows indicate the deviation of three measurements.

Figure 11 demonstrates the sensitivity of the employed amperometry: The solution was injected into the aqueous solution via a Rheodyne valve in a loop (volume: $10 \mu \mathrm{L}$ ) and was pumped through an electrochemical HPLC cell with an SPE inside (pump rate: $1 \mathrm{~mL} /$ $\min )$. The applied potential was $0.5 \mathrm{~V}$.

After each measurement the SPE was carefully polished with aluminum oxide powder. The LOD with $\mathrm{AM}$ is about $10 \mathrm{ng}=1 \mathrm{mg} / \mathrm{L}$ (Figure 11). The saturation at about $200 \mathrm{ng}$ triclosan is lower than for the (batch) DPV. With the (lowest) HPLC-pumping rate of $1 \mathrm{~mL} / \mathrm{min}$ and an AM sampling rate of $0.1 \mathrm{~s}$, the time constant is too high to resolve higher concentrations of triclosan (i.e., the effective electrode area is smaller than the real area).

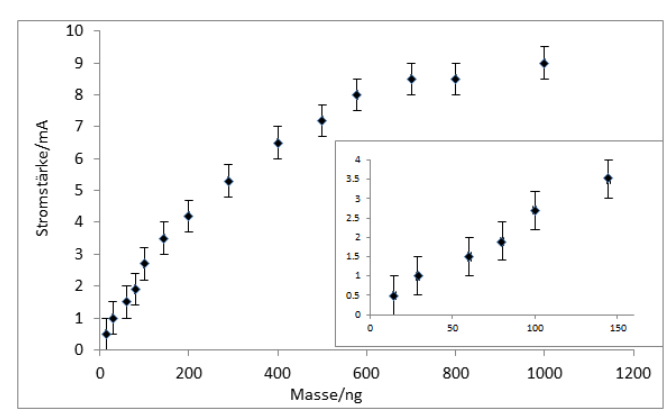

Figure 11: Amperometric detection of triclosan at $0.5 \mathrm{~V}$.

\section{Electrogenerated Chemiluminescence (ECL)}

Since the 1960s, the ECL technique has become increasingly attractive in analytical chemistry [45-52]. ECL involves generating an excited state in the commonly used and extensively investigated tris(2, 2'-bipyridyl)ruthenium (II) $\left(\left[\mathrm{Ru}(\mathrm{bpy})_{3}\right]^{2+}\right)$ on an electrode surface. First, the $\left[\mathrm{Ru}(\mathrm{bpy})_{3}\right]^{2+}$ is oxidized and then undergoes an electrontransfer reaction with a coreactant. During the latter process, an excited state is created that subsequently decays and light is emitted. ECL represents a "marriage of electrochemical and spectroscopic methods" [50]. The ECL system used is a combination of $\left[\mathrm{Ru}(\mathrm{bpy})_{3}\right]^{2+}$ and proline (as coreactant), which produces one of the most intense ECL results [53]. In addition, this system has excellent water solubility and is less toxic than tripropylamine, one of the most common coreactants in ECL studies (Table 1). By adding triclosan, the ECL is quenched. This quenching can be used to quantitatively determine triclosan. Figure 12 shows the ECL quenching of triclosan at a concentration of $50 \mu \mathrm{mol} / \mathrm{L}(=14 \mathrm{mg} / \mathrm{L})$. This is the lowest concentration of triclosan which quenches the ECL of $\mathrm{Ru}^{2+} /$ proline, a value which is about twenty times higher than DPV. A further disadvantage of this method is the low reproducibility (see the error bar in Figure 12).

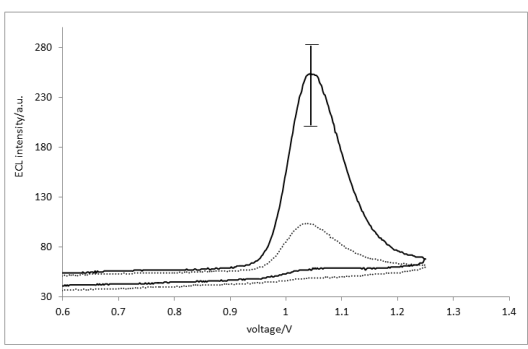

Figure 12: Solid line: ECL of $50 \mu \mathrm{mol} / \mathrm{L}\left[\mathrm{Ru}(\mathrm{bpy})_{3}\right]^{2+}+50 \mu \mathrm{mol} / \mathrm{L}$ proline with error bar. Dotted line: ECL of $50 \mu \mathrm{mol} / \mathrm{L}\left[\mathrm{Ru}(\mathrm{bpy})_{3}\right]^{2+}$ $+50 \mu \mathrm{mol} / \mathrm{L}$ proline $+50 \mu \mathrm{mol} / \mathrm{L}$ triclosan.

\begin{tabular}{|l|l|l|}
\hline Method & $\begin{array}{l}\text { Limit } \\
\text { Detection } \\
\text { (LOD) }\end{array}$ & Estimation \\
\hline MS & $0.15 \mathrm{mg} / \mathrm{L}$ & $\begin{array}{l}\text { Expensive, low LOD, convenient } \\
\text { method for simultaneous detection of a } \\
\text { wide range of substances. }\end{array}$ \\
\hline DPV & $0.7 \mathrm{mg} / \mathrm{L}$ & $\begin{array}{l}\text { Easy to use, cleaning procedure is } \\
\text { needed for electrodes. }\end{array}$ \\
\hline AM & $1 \mathrm{mg} / \mathrm{L}$ & $\begin{array}{l}\text { Easy to use, appropriate method in } \\
\text { combination with HPLC. }\end{array}$ \\
\hline ECL & $14 \mathrm{mg} / \mathrm{L}$ & $\begin{array}{l}\text { Information about quenching the } \\
\text { chemiluminescence of [Ru(bpy) }]_{3}^{2+} \\
\text { comparably low reproducibility. }\end{array}$ \\
\hline Voltabsorptometry & - & $\begin{array}{l}\text { Two-dimensional spectroscopy: } \\
\text { information about electrochemical and } \\
\text { optical properties. }\end{array}$ \\
\hline
\end{tabular}

Table 1: Summary of the methods used.

\section{Reductive dehalogenation of triclosan with zero-valent iron}

The dechlorination procedure is described in detail by Aristov and Habekost [40,41]. Some fundamental aspects are explained here: The reactor is a V2A stainless steel tube $18 \mathrm{~mm}$ dia. and $700 \mathrm{~mm}$ long. About $20 \mathrm{~g}$ of iron powder are gently mixed with a $0.5 \mathrm{~g}$ tuft of glass wool in a rotary mixer until a low density homogeneous fluffy powder is obtained. This is poured into the tube to a length of about $200 \mathrm{~mm}$. The reactor is heated with a hinged tube furnace. The operating mode of the reactor is conceived so as to allow injection of condensed phase reactants under controlled, prolonged, continuous flow conditions. In 
tests with toluene or propanol as the proton donor, triclosan and toluene or propanol are mixed in a separate vessel, in a mass ratio of $1: 5$, and then transferred to a $100 \mathrm{~mL}$ syringe. The syringe is depressed by a perfusor so that the liquid solution is injected into the reactor tube at a rate of about $1 \mathrm{~mL}$ per $10 \mathrm{~s}$ and vaporized inside.

A nitrogen gas stream (at about $10 \mathrm{~mL} / \mathrm{min}$ flow rate) transports the gaseous reactants and dehalogenation products through the tube. Upon exiting the tube, the products are condensed in a cooled trap and then taken to an offline GC-MS for analysis (via micro-syringe extraction). Figure 13 shows a schematic of the apparatus.

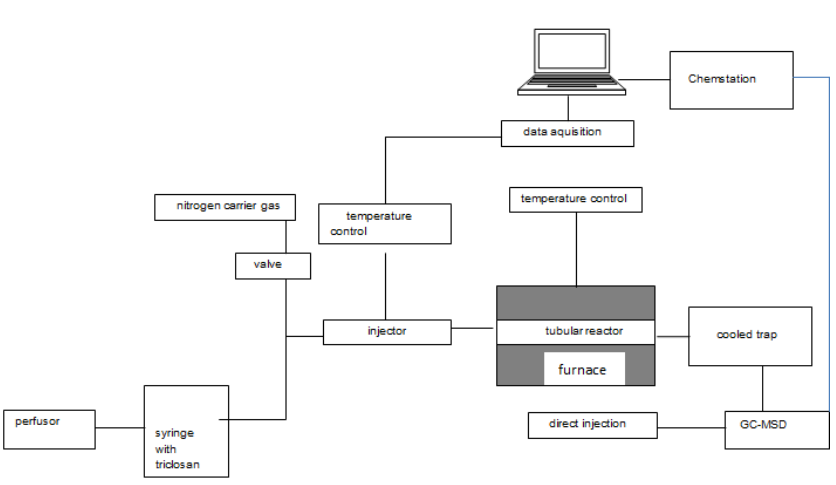

Figure 13: Schematic of the dechlorination apparatus.

The duration of contact between the triclosan and the dehalogenating iron is between $15 \mathrm{~s}$ and $20 \mathrm{~s}$, depending on the reactor temperature. This was determined by injecting the triclosan into the reactor at the front and end of the tube, directly into the ice-cooled trap. The difference in detection times is the transit time through the reactor. Detailed kinetics studies were not attempted. However, since the iron and the proton source are both present in excess, a (pseudo) first-order reaction is likely, with a half-life of less than $15 \mathrm{~s}$.

The gas chromatographs show significant reduction of the signals corresponding to the triclosan at temperatures as low as $400^{\circ} \mathrm{C}$. However, temperatures of about $550^{\circ} \mathrm{C}$ are required to achieve the intended goal of "complete" conversion: at these temperatures, a comparison of the peak heights shows that conversion rates of better than $99 \%$ are achieved (Figure 14).

Figure 15 shows that the peaks between 9 and $15 \mathrm{~min}$ at $550^{\circ} \mathrm{C}$ were all checked against the NIST database for MS and correspond unequivocally to various condensation products of toluene and phenyl.

As can be seen from Table 2, no chlorine organic substance, especially no chlorinated dibenzodioxine, were detected.

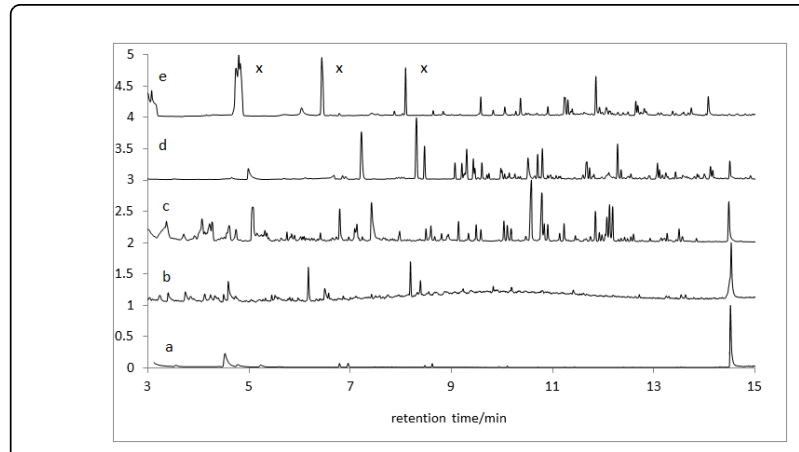

Figure 14: Gas phase dehalogenation at different temperatures: a) direct injection b) $\left.\left.300^{\circ} \mathrm{C} \mathrm{c}\right) 400^{\circ} \mathrm{C} \mathrm{d}\right) 500^{\circ} \mathrm{C}$ e) $550^{\circ} \mathrm{C}$. The GCs were normalized on the maximal product concentration (no internal standard was used) $\mathrm{x}=$ not to be identified.

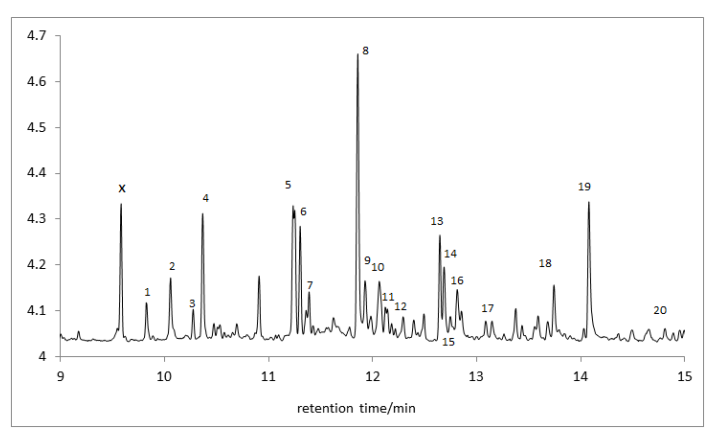

Figure 15: Part of Figure $14\left(550^{\circ} \mathrm{C}\right)$. The numbers correspond to Table $2 . \mathrm{x}=$ not to be identified.

\begin{tabular}{|l|l|l|l|}
\hline Peak & Substance (quality $\mathbf{9 0 \% )}$ & Peak & Substance (quality $\mathbf{9 0 \% )}$ \\
\hline 1 & Dibenzofuran & 11 & Phenylphenole \\
\hline 2 & Diphenyl ether & 12 & Diphenylethene \\
\hline 3 & Dibenzodioxin & 13 & Methylanthracene \\
\hline 4 & Fluorene & 14 & Methylanthracene \\
\hline 5 & Methylfluorene & 15 & Phenanthrene \\
\hline 6 & Methylfluorene & 16 & $?$ \\
\hline 7 & Methylfluorene & 17 & Naphthalene derivate \\
\hline 8 & Anthracene & 18 & Pyrene \\
\hline 9 & Anthracene & 19 & Pyrene \\
\hline 10 & Fluorene derivate & 20 & Methylpyrene \\
\hline
\end{tabular}

Table 2: Assignment of the peaks from Figure 15.

\section{Further work}

A) Analytics: Does the Selected Ion Monitor (SIM) modus in mass spectrometry give a better LOD? Does a lower pumping rate influence saturation in amperometry? 
Page 7 of 8

B) Dehalogenation: In a previous work we were able to show that a mixture of iron and quicklime shows great promise for incorporation in soil and sediment remediation processes, but several questions remain. First, we observed that the empty steel tube by itself, with no iron powder inside, is also capable of complete conversion of the OCs, but at higher temperatures (above $600^{\circ} \mathrm{C}$ ). Presumably, reducing the iron powder grain size (e.g., to nanometer scales) will allow efficient dehalogenation to proceed at even lower temperatures than necessary in the work presented here. Second, since water must be added to the triclosan/quicklime mixture to produce the calcium hydroxide proton donor, dehalogenation efficiency should be tested under conditions with an excess of water, to more closely simulate actual contaminated soil conditions. Third, replacing the nitrogen carrier gas with air should be tested. Especially, does any chlorinated dibenzodioxine result in the air-filled tube?

\section{Results and Discussion}

The total ion signal intensity of the triclosan peak at different concentrations is shown in Figure 3. The LOD (signal:noise $=3: 1$ ) is about $0.15 \quad \mathrm{mg} / \mathrm{L} \quad(=0.52 \mu \mathrm{mol} / \mathrm{L})$. Derivatization with trimethylchlorosilanes substitutes the phenolic group by forming a trimethylsilyl derivative. But derivatization does not lead to lower detection limit. Unexpectedly, dichlorodibenzodioxin is formed at higher temperatures.

Electrochemistry plays an important role in the analytics of triclosan. Commercial SPE are suitable for rapid and inexpensive electrochemical screening technique. The results especially with DPV and AM technique are suitable for field measurements and screening. Spectroelectrochemical measurements deliver additional information about the resulting electrochemical oxidation products. ECL can be used if the substance under investigation can influence the ECL of the $\left[\mathrm{Ru}(\mathrm{bpy})_{3}\right]^{2+}$ used. But the LOD of the ECL method in case of triclosan is much higher than the LOD of DPV and AM. The plots of the dependence of the peak currents on the triclosan concentrations are linear between $0.7 \mathrm{mg} / \mathrm{L}$ and $200 \mathrm{mg} / \mathrm{L}$ for DPV and between $1 \mathrm{mg} / \mathrm{L}$ and $15 \mathrm{mg} / \mathrm{L}$ for AM.

Figure 14 shows gas chromatograms of triclosan at different reductive dehalogenation temperatures. One sees that $550^{\circ} \mathrm{C}$ is sufficient for dehalogenation to occur, as the triclosan disappears from the chromatogram and no chlorinated product are exciting in the tube, confirmed by the analysis of the products.

\section{Conclusion}

This paper has described three (spectro) electrochemical methods for identifying triclosan: DPV, AM and ECL. We have shown that these methods have different LODs, and the ECL signal has the disadvantage that reproducibility is poor. The Au electrode used has to be cleaned before every measurement because the oxidation product forms a passivating polymeric film on the electrode surface.

The electrochemical methods give a preliminary estimation of the triclosan concentrations. The advantages of the screen-printed electrodes used are their easy handling and their rapid feasibility. Mass spectrometry can provide more reliable determination of triclosan for suspicious samples.

\section{Acknowledgements}

Achim Habekost thanks the Vector foundation, the Fonds der Chemischen Industrie and the University of Ludwigsburg for financial support.

\section{References}

1. Science Committee on Consumer Safety SCCS, European Union, 2010.

2. Welsch TT, Gillock ET (2011) Triclosan-resistant bacteria isolated from feedlot and residential soils. J Environ Sci Health: Part A 46: 436-440.

3. Hammond SM, Lambert PA, Rycroft AN (1984) The Bacterial Cell Surface. London \& Sydney: Croom Helm Vol. 59.

4. Schweizer HP (2001) Triclosan: a widely used biocide and its link to antibiotics. FEMS Microbiology Letters 202: 1-7.

5. Russell AD (2004) Whither triclosan? J Antimicrobial Chemotherapy 53: 693-695.

6. Dejmkova H, Kwiencien J, Cizek K, Cermak J, Vranova E, et al. (2014) Voltammetric and LC-MS/MS Method for the Determination of Triclosan - A Comparative Study, Validation and Simultaneous Application. Intern J Electrochem Sci 9: 139-147.

7. Tohidi F, Cai Z (2017) Fate and mass balance of triclosan and its degradation products: Comparison of three different types of wastewater treatments and aerobic/anaerobic sludge digestion. J Hazard Mat 323: 329-340.

8. Ramaswamy BR, Shanmugam G, Velu G, Bhuvaneshwari R, Larsson DGJ (2011) GC-MS analysis and ecotoxicological risk assessment of triclosan, carbamazepine and parabens in Indian rivers. J Haz Mat 186: 1586-1593.

9. Zheng C, Zhao J, Bao P, Gao J, He J (2011) Dispersive liquid-liquid microextraction based on solidification of floating organic droplet followed by high-performance liquid chromatography with ultraviolet detection and liquid chromatography-tandem mass spectrometry for the determination of triclosan and 2,4-dichlorophenol in water samples. J Chromatogr 1218: 3830-3836.

10. van Stee LLP, Leonards PMG, Vreuls RJJ, Brinkman UAT (1999) Identification of non-target compounds using gas chromatography with simultaneous atomic emission and mass spectrometric detection (GCAED/MS): analysis of municipal wastewater. Analyst (Cambridge, United Kingdom) 124: 1547-1552.

11. Singer H, Muller S, Tixier C, Pillonel L (2002) Triclosan: Occurrence and Fate of a Widely Used Biocide in the Aquatic Environment: Field Measurements in Wastewater Treatment Plants, Surface Waters, and Lake Sediments. Environmental Science and Technology 36: 4998-5004.

12. Okumura T, Nishikawa Y (1996) Gas chromatography- mass spectrometry determination of triclosans in water, sediment and fish samples via methylation with diazomethane. Analytica Chimica Acta 325: 175-184.

13. Na NW, Wang Y, Zhu S, Jinmao JY, Zhao XE, et al. (2017) Rapid and sensitive determination of multiple endocrine- disrupting chemicals by ultrasound- assisted in situ derivatization dispersive liquid- liquid microextraction coupled with ultra- high- performance liquid chromatography/tandem mass spectrometry. Rapid Communications in Mass Spectrometry: RCM 31: 937-950.

14. Lu H, Ma H, Tao G (2009) Spectrophotometric determination of triclosan in personal care products. Spectrochem Acta Part A: Molec Biomolec Spectr 73: 854-857.

15. Yang JQ, Wang P, Zhang XJ, Wu KB (2009) Electrochemical Sensor for Rapid Detection of Triclosan Using a Multiwall Carbon Nanotube Film. J Agric Food Chem 57: 9403-9407.

16. Dai H, Xu GF, Gong LS, Yang CP, Lin YY, et al. (2012) Electrochemical detection of triclosan at a glassy carbon electrode modified with carbon nanodots and chitosan. Electrochem Acta 80: 362-367.

17. Tsai TH, Thiagarajan S, Chen SM (2011) Electrochemical Fabrication of Nano TiO2 Bilayer Film Modified Electrode and Electroanalytical Applications. Int J Electrochem Soc 6: 3878-3889. 
18. Pemberton RM, Hart JP (1999) Electrochemical behavior of triclosan at a screen-printed carbon electrode and its voltammetric determination in toothpaste and mouthrinse products. Anal Chim Acta 390: 107-115.

19. Montaseri H, Forbes PBC (2016) A review of monitoring methods for triclosan and its occurrence in aquatic environments. Trends Anal Chem 85: 221-231.

20. Mouatassim-Souali A, Tamisier-Karolak SL, Perdiz D, Cargouet M, Levi Y (2003) Validation of a quantitative assay using GC /MS for trace determination of free and conjugated estrogens in environmental water samples. J Sep Sci 26: 105-111.

21. Kelly C (2000) Analysis of steroids in environmental water samples using solid- phase extraction and ion- trap gas chromatography- mass spectrometry and gas chromatography- tandem mass spectrometry. J Chromatogr A 872: 309-314.

22. Rodriguez I, Quintana JB, Carpinteiro J, Carro AM, Lorenzo RA, et al. (2003) Determination of acidic drugs in sewage water by gas chromatography- mass spectrometry as tert.- butyldimethylsilyl derivatives. J Chromatogr A 985: 265-274.

23. Ollers S, Singer HP, Fassler P, Muller SR (2001) Simultaneous quantification of neutral and acidic pharmaceuticals and pesticides at the low-ng/L level in surface and waste water. J Chromatogr A 911: 225-234.

24. Yu Z, Peldszus S, Huck PM (2007) Optimizing gas chromatographic-mass spectrometric analysis of selected pharmaceuticals and endocrine disrupting substances in water using factorial experimental design. J Chromatogr A 1148: 65-77.

25. Armstrong DL, Lozano N, Rice CP, Ramirez M, Torrents A (2018) Degradation of triclosan and triclocarban and formation of transformation products in activated sludge using benchtop bioreactors. Environ Res 161: 17-25.

26. Song Z, Wang N, Zhu L, Huang A, Zhao X, et al. (2012) Efficient oxidative degradation of triclosan by using an enhanced Fenton- like process. Chem Eng J 198-199: 379-387.

27. Munoz M, de Pedro ZM, Casas JA, Rodriguez JJ (2012) Triclosan breakdown by Fenton-like oxidation. Chem Eng J 198-199: 275-281.

28. Constantin LA, Nitoi I, Cristea NI (2018) Possible degradation pathways of triclosan from aqueous systems via $\mathrm{TiO} 2$ assisted photocatalysis. J Indust Eng Chem 58: 155-162.

29. Liu H, Cao X, Liu G, Wang Y, Zhang N, et al. (2013) Photoelectrocatalytic degradation of triclosan on $\mathrm{TiO} 2$ nanotube arrays and toxicity change. Chemosphere 93: 160-165.

30. Zhai P, Chen X, Dong W, Li H, Chovelon JM (2017) Degradation of triclosan in the presence of $\mathrm{p}$ - aminobenzoic acid under simulated sunlight irradiation. Environ Sci Pollut Res 24: 558-567.

31. Ren YZ, Franke M, Anschuetz F, Ondruschka B, Ignaszak A (2014) Sonoelectrochemical degradation of triclosan in water. Ultrason Sonochem 21: 2020-2025.

32. Yu JC, Kwong TY, Luo Q, Cai Z (2006) Photocatalytic oxidation of triclosan. Chemosphere 65: 390-399.

33. Yang B, Ying GG, Zhao JL, Zhang LJ, Fang YX, et al. (2011) Oxidation of triclosan by ferrate: Reaction kinetics, products identification and toxicity evaluation. J Haz Mat 186: 227-235.

34. Wu Q, Shi H, Adams CD, Timmons T, Ma Y (2012) Oxidative removal of selected endocrine- disruptors and pharmaceuticals in drinking water treatment systems, and identification of degradation products of triclosan. Sci Total Environ 439: 18-25.
35. de Leon-Condes C, Barrera-Diaz C, Barrios J, Becerril E (2017) A coupled ozonation- electrooxidation treatment for removal of bisphenol A, nonylphenol and triclosan from wastewater sludge. Int J Environ Sci Technol 14: 707-716.

36. Moyo M, Florence LR, Okonkwo JO (2015) Improved electro-oxidation of triclosan at nano-zinc oxide-multiwalled carbon nanotube modified glassy carbon electrode. Sens Actuators B 209: 898-905.

37. Orhon AK, Orhon KB, Yetis U, Dilek FB (2017) Triclosan removal from surface water by ozonation - Kinetics and by- products formation. J Environ Manag 204: 327-336.

38. Gao Y, Ji Y, Li G, An T (2014) Mechanism, kinetics and toxicity assessment of $\mathrm{OH}$ - initiated transformation of triclosan in aquatic environments. Water Res 49: 360-370.

39. Suarez S, Dodd MD, Omil F, von Gunten U (2007) Kinetics of triclosan oxidation by aqueous ozone and consequent loss of antibacterial activity: Relevance to municipal wastewater ozonation. Water Res 41: 2481-2490.

40. Aristov N, Habekost A (2010) Heterogeneous dehalogenation of PCBs with iron/toluene or iron/quicklime. Chemosphere 80: 113-115.

41. Habekost A, Aristov N (2012) Heterogeneous reductive dehalogenation of PCB contaminated transformer oil and brominated diphenyl ethers with zero valent iron. Chemosphere 88: 1283-1286.

42. Gibson R, Becerril E, Silva-Castro V, Jimenez B (2007) Determination of acidic pharmaceuticals and potential endocrine disrupting compounds in wastewater and spring waters by selective elution and analysis by gas chromatography - mass spectrometry. J Chromatogr A 1169: 31-39.

43. Gattrell M, Kirk DW (1993) A study of electrode passivation during aqueous phenol electrolysis. J Electrochem Soc 140: 903-911.

44. Johnson SK, Houk LL, Feng J, Houk RS, Johnson DC, et al. (1999) Electrochemical Incineration of 4-Chlorophenol and the Identification of Products and Intermediates by Mass Spectrometry. Environ Sci Technol 33: $2638-2644$

45. Birks JB (1989) Chemiluminescence and Photochemical Reaction in Chromatography. VCH, New York.

46. Baeyens WRG, de Keukeleire D, Korkidis K (1991) Luminescence techniques in chemical and biochemical analysis. Marcel Dekker, New York.

47. Miao W, Choi JP, Bard AJ (2002) Electrogenerated Chemiluminescence 69: The Tris(2, 2'- bipyridine) ruthenium(II), ([Ru(bpy) 3]2+)/Tri- npropylamine (TPrA) System Revisited - A New Route Involving TPrA •+ Cation Radicals. J Am Chem Soc 124: 14478-14485.

48. Kapturkiewicz A (1995) Electrogenerated chemiluminescence from the tris(2, 2'- bipyridine) ruthenium(II) complex. Chem Phys Lett 236: 389-394.

49. Hercules DM, Lytle FE (1966) Chemiluminescence from reduction reactions. J Am Chem Soc 88: 4795-4796.

50. Richter MM (2004) Electrochemiluminescence (ECL). Chem Rev 104 3003-3036.

51. Parveen S, Aslam MS, Hu L, Xu G (2013) Electrogenerated Chemiluminescence. Protocols and Applications. Springer, Heidelberg.

52. Bard AJ (2004) Electrogenerated Chemiluminescence. Marcel Dekker, New York.

53. Habekost A (2016) Investigations of some reliable electrochemiluminescence systems on the basis of tris(bipyridyl)Ruthenium(II) for HPLC analysis. World J Chem Educ 4: 13-20. 